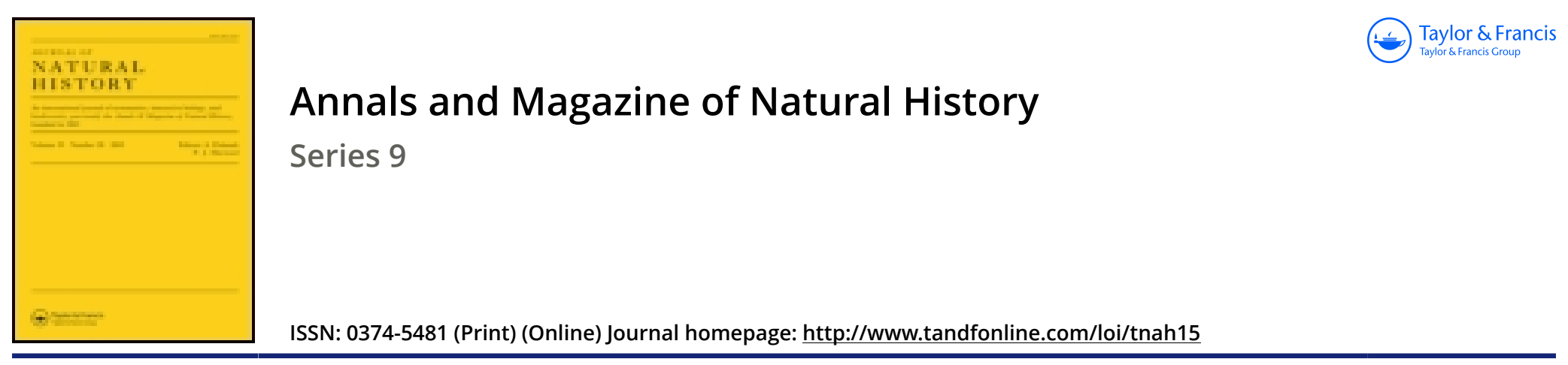

\title{
XXIX.-A subdivision of the genus Uromys
}

\section{Oldfield Thomas}

To cite this article: Oldfield Thomas (1922) XXIX.-A subdivision of the genus Uromys, Annals and Magazine of Natural History, 9:51, 260-261, DOI: 10.1080/00222932208632669

To link to this article: http://dx.doi.org/10.1080/00222932208632669

册 Published online: 04 Sep 2009.

Submit your article to this journal

LII Article views: 6

Q View related articles $\asymp$ 


\section{XXIX.-A Subdivision of the Genus Uromys. By Oldfield Thomas.}

(Published by permission of the Trustees of the British Museum.)

THe genus Uromys, which ranges from the Moluccas through New Guinea and the Solomon Islands to North Australia, has long been known to fall naturally into two very distinct groups. These have been by myself spoken of as the large species allied to $U$. macropus and the small ones allied to U. bruijnii. Now, however, in connection with the working out of some New Guinea mammals, I have had occasion to examine them more closely, and find that the differences are such that these groups may very well be treated as genera. In addition, the remarkable species U. sapientis of the Solomon Islands would seem also to deserve generic separation.

The three genera may be distinguished as follows:-

A. Skull with projecting zygomatic plate. Bullæ very small, little inflated. Masopterygoid fossa broad anteriorly, the palatal edge level with or behind $m^{3}$.

a. Size large, hind foot $52 \mathrm{~mm}$. and upwards, skull-length $60 \mathrm{~mm}$. and upwards. T'ail long, commonly with contrasted white tip. Palatine foramina very short, their length not more than the distance from their hinder end to $m^{1}$. Back of palate bohind level of hinder edge of $\mathrm{m}^{3}$. Incisors very deep in proportion to their breadth, the depth of the lower ones equalling the combined breadth of the pair. Palate-ridges, where known, consisting of a large number (12 or more) of fine interdental ridges*, besides the usual predental ridges .....................

Synonym : Gymnomys, Gray.

Genotypes of both names: U. macropus t, Gray.

Range: New Guinea, Aru Islands, and N. Queensland.

Species described : anak, aruensis, macropus, maltiplicatus, nero, papuanus, rothschildi, scaphax, validus.

b. Size smaller, the largest with hind foot $43 \mathrm{~mm}$. and skull 51 mm., but the majority far smaller. Tail usually shorter than in Uromys, though occasionally long, either wholly black, or lighter below, but not known

* As figured by Jentink, ' Nova Guinea,' v. pl. xvi. fig. 6.

+ Palmer erroneously givea celebensis as the genotype of Gymnomys ; but a reference to P. Z. S. 1867, P. 597, paragraph 5, will show that the genotype is "Mus maeropus." 
to have an abruptly white tip. Palatine foramina not so short as in Uromys, their length approximating to once and a half the distance from their hinder end to the mulars. Mesopterygoid fossa broad anteriolly; back of palate about at level of $m^{3}$. Incisors normal, not specially deep in proportion to their breadth, the depth of the lower ones not equalling the combined breadth of the pair. Palate-ridges, where known, consisting of about 5 or 6 interdental ridges in addition to the simple predental ones* .......... II. Melomys.

Genotype: $M$. rufescens $\dagger$ (Uromys rufescens, Alst.).

Range: Melanesia in a broad sense-from the Talaut Islands and Molnceas through New Guinea to the Solomon Islands, and oouthwards to North Australia.

Species described: arosts, arcium, bruijnin, calidor, caurinus, cervinipes, fraterculus, fulgens, gracilis, leucogaster, levipes, iorentzi, lutillus, melicus, mollis, moncktoni, murinus, musavora, muscalis, naso, obiensis, platyops, porculus, rufescens, stalkeri, talaudium.

B. Skull with zygomatic plate scarcely projecting.

Bullæe comparatively large, inflated. Mesopterygoid fossa narrowed anteriorly to a point, which is level with the hinder edge of $m^{2}$.

a. Size of the single species rather large. Tail medium, wholly black. Palatine foramina about as in Melomys. Incisors broad and stout, the lower ones not deep in proportion to their width. Palate-ridges not known .. III. Solomys.

Genotype and sole species: S. sapientis (Uromys sapientis, Thos.).

Range : Solomon Islands only.

\section{XXX.-New Mammals from New Guinea and neighbouring 1slands. By Oldfield Thomas.}

(Published by permission of the Trustees of the British Museum.)

BY the kindness of Dr. W. K. Dammerman of Buitenzorg I have been entrusted with the examination of the considerable number of Papuan mammals in the Museum under his care, the majority of them coming from recent expeditions to New Guinea, notably that of 1920 to the Mamberano-Idenburg region of $\mathrm{N}$. New Guinea, carried out by Mr. W. C. van Heurn.

* As figured by Jentink, tab. cit. fig. 3 .

+ Chosen because $I$ happen to be able to check the number of palateridges in one of the typical specimens. 